\title{
Financial Performance Analysis of Backdoor Listed Companies
}

\author{
Huang Yuhong \\ Huazhong University of Science and Technology, Room 502, Building Deya, LuohuHuayuan, ShishanTownship, Foshan City, China
}

\begin{abstract}
IPO listing threshold requirements are high, many enterprises have chosen to backdoor listing due to the restrictions of objective factors. In order to study the impact of backdoor listing on corporate financial performance, this paper adopts the method of case analysis and takes SF Express, a typical representative of express delivery industry, as an example to analyze whether SF Express has improved its financial performance after backdoor listing by using financial indicators such as debt paying ability, operating ability, profitability and growth ability. The results show that the overall financial performance of SF Express has been improved due to the sufficient capital and the expansion of business scope. The innovation of this paper lies in the horizontal short-term comparison of financial data of SF Express which is backdoor listed and DEPPON Express which is IPO listed in express industry. The research shows that backdoor listing is more conducive to the improvement of the financial performance of enterprises in the short term, providing certain reference value for enterprises that want to go public by backdoor listing in the express industry in the future. However, when deciding to go public, different enterprises should choose suitable listing schemes according to their own financial characteristics and understand the risk and the strategic goal of the enterprise's own development.
\end{abstract}

\section{Introduction}

With the advent of the Internet, the rise of e-commerce has also made progress in the express delivery industry. Moreover, the country has also clearly shown its support for the development of the express delivery industry. By improving China's transportation system and introducing relevant favorable policies, China's express delivery business in the first half of 2018 alone has exceeded 22.08 billion, and its operating income has also reached 274.5 billion yuan. This also shows that the overall development potential of the express delivery industry is great and the development prospects are bright.

However, in the face of increasingly fierce competition in the industry, in order to maintain their market share and further divide up a larger market share, various express delivery companies have to reduce the price of services. Private enterprises have limited internal financing. In order to keep corporate profits from falling, they urgently need to increase investment in infrastructure and innovative technologies through listed financing to reduce service costs. The financing advantages of the capital market make every express company want to enter, but in the face of the strict conditions of IPO and time cost, major private enterprises have stepped down and turned to backdoor listing. Therefore, in the express delivery industry, STO. Express first successfully listed in China through backdoor. Subsequently, many of the better performing companies in the express delivery industry succeeded in going public through backdoors, raising more funds and expanding the scale of their operations.

SF originally had a leading position in the express delivery industry with its many advantages such as its direct operation model and its own airline. However, facing the predicament of enterprises in the same industry with capital advantages and insufficient capital of their own companies, in order to adapt to changes in demand and maintain the level of SF's advantages in the industry, listing financing is imminent. So in 2017, SF entered the A-share market through backdoors.

In order to analyze the financial performance of backdoor listed companies, this paper starts from the express delivery industry and analyzes it with its typical representative SF Company as an example. This paper first discusses the motivation and purpose of SF backdoor listing to understand the necessity of SF listing. Then the paper compares and analyzes the financial data before and after the listing to demonstrate whether the backdoor listing is conducive to the financial performance of the company and helps companies that want to list in the future to learn whether it is suitable for backdoor listing. At the same time, I also hope that this paper will have a positive guiding significance for the future trend of the express delivery industry.

\section{Literature review}

Private enterprises have limited funds and must enter the capital market for financing in order to expand production. Backdoor listings provide another relatively easy way for 
many companies to go public. Although China's backdoor listing has appeared for less than 30 years, a large number of private enterprises have successfully listed through this method. Many scholars have conducted related research and discussion on backdoor listing, which are mainly divided into motivation analysis and business performance analysis.

For the motivation of backdoor listing, the existing literature research is mainly as follows: $\mathrm{Xu}$ Wei and Pei Zhehui (2011) believe that IPO review takes a long time, and the company's eagerness for financing is the main reason for backdoor listing. Peng Xiaojie (2011) believes that going public can get a lot of funds at low cost, which is conducive to the development of enterprises in competition. Li Sha (2014) believes that in recent years, the government has continuously issued relevant policies to encourage companies to list through backdoors. Ma Leihui (2015) believes that the reasons for the backdoor listing of private enterprises should be divided into backdoor parties, shell companies and external factors for analysis and discussion. Feng Baiyang (2016) believes that the capital advantage of backdoor listing can help companies transform their operations and improve the company's structure. Wang Dong and Chen Jianli (2018) believe that the fundamental reason for the company's listing is the superiority of the capital market. After the listing, the company can allocate shares and issue bonds to make the company funds more adequate. Gao Yiyi (2018) believes that backdoor listing can increase corporate visibility and enjoy some preferential policies, which are also important motivations. Therefore, the study of the motivation is discussed by scholars from the backdoor and the shell side, as well as from the external and internal causes. Most scholars agree that the need for the company's own funds and the high IPO threshold are the reasons for the company's backdoor listing.

For the performance of backdoor listed companies, existing studies have mainly studied from the following two aspects:

First, whether the performance of backdoor listed companies before and after listing has been optimized. Zhang Xiaoqian (2009) conducted empirical analysis of a large number of backdoor listing cases, and found that the performance of most companies in the first two years after listing is better than that before listing; Jiang Shuangna (2011) compared the financial indicators before and after the listing of the company, and found that the performance of the company after listing is better than before the listing. However, Qiu Qun (2013) found that the operating performance of enterprises before and after the backdoor listing has not change much, and believed that backdoor listing does not affect the business performance of the enterprises. Lin Xiang (2017) analyzed the changes in financial performance before and after the listing through the event study and DuPont analysis method, and found that after the listing of YTO Express, the sufficient funding source has stimulated the development of the company. Liu Qing and Yang Zifeng (2018) used the financial statement data of the backdoor listed companies to select financial indicators and analyzed that the financial performance of the companies after the backdoor listing has improved. Shi Xinke (2018) compared the backdoor listing data of YTO Express and Yunda Holding Co., Ltd., and the research showed that backdoor listing provides an effective financing channel for express private enterprises and improves their profitability and other capabilities. Zhao Hong (2018) conducted a factor analysis of the financial performance of STO Express's backdoor listing. Through the analysis, it is concluded that the business performance of STO Express has been enhanced and its competitive strength has been enhanced due to the enhancement of financing ability after STO Express's backdoor listing.

Second, the impact of listing methods on operating performance after listing. Peidong Sun (2014) studied a large number of cases and found that companies listed through an IPO performed better than companies listed through a backdoor. Ju Fanglin (2014) has the same research results as Sun Peidong, who believes that backdoor listing can increase the amount of financing and promote better development of enterprises. Zhang Ye (2015) research found that in the two years before listing, the financial performance of backdoor listed companies was significantly better than that of IPO listed companies, but the performance differences after that were not significant. Ma Xinyue (2018) compared the performance of IPO and backdoor listed companies from 2010 to 2017 and concluded that the mode of listing has little impact on the long-term development of the company.

In summary, many scholars conduct research and analysis on the operating performance of backdoor listed companies. Most scholars believe that the operating performance of listed companies is better after listing, but a few scholars have found that listing has little effect on operating performance. The results of the research on the way in which listing methods affect companies are even more disparate. Therefore, this paper takes SF Express as an example. Based on the motivation analysis, the horizontal and vertical comparison of SF's financial indicators is used to analyze the impact of backdoor listing on the financial performance of the company for reference in subsequent research.

\section{Financial Performance of SF Backdoor Listing}

In order to analyze the performance of financial performance, this chapter first selects financial indicators, uses debt-servicing indicators, operational indicators, and profitability indicators that can be compared horizontally and vertically, and further analyzes the growth of the company. In order to compare the changes in the financial status of SF backdoor before and after listing, this chapter selects the financial data of SF annual financial statements from 2014 to 2017 for vertical comparison and analysis. Then this chapter compares the impact of the listing method on the financial performance of the company, analyzes and compares the financial performance of IPO listed DEPPON Express and backdoor listed SF in the first year of listing, and draws corresponding conclusions. 


\subsection{Selection of financial indicators}

To objectively evaluate the difference in financial performance before and after the SF backdoor listing, in addition to combining relevant direct data, it is necessary to comprehensively consider all aspects and select financial indicators that are operable and can be compared horizontally and vertically. This paper has selected the following indicators:

(1) Solvency: reflects the ability of an enterprise to bear its debts. Short-term solvency indicators include current ratios and quick ratios, which are directly proportional to short-term solvency. The long-term solvency index includes the asset-liability ratio. The higher the ratio, the higher the corporate debt and the greater the long-term debt repayment pressure; but the lower the ratio will also restrict the development of the enterprise;

(2) Operating capacity: It is used to measure the asset management ability and capital turnover ability of an enterprise. Accounts receivable turnover rate and total assets turnover rate respectively reflect the liquidity efficiency of accounts receivable and total assets;

(3) Profitability: The purpose of business operation is to make profits. The sales profit rate reflects the proportion of the profit level of the company's sales income; the total asset return rate reflects the company's total asset income ability, and the difference between the return on equity and the net asset rate can reflect the risk of the business,

(4) Development capacity: The company's net profit, operating income, and total assets are important factors for the sustainable development of the company in market competition. To measure the market scale and development speed of an enterprise, you can use the yearon-year growth rate of these data to see the company's growth.

\subsection{Vertical comparison of financial performance}

Table 1 Annual data of SF Holdings

\begin{tabular}{ccccc}
\hline PROJECT & YEAR 2014 & 2015 YEAR & 2016 YEAR & 2017 YEAR \\
\hline CURRENT ASSETS & $1,566,662.67$ & $1,858,248.76$ & $2,133,317.48$ & $3,148,962.08$ \\
STOCK & $38,932.07$ & $25,609.79$ & $39,601.37$ & $44,635.90$ \\
ACCOUNTS RECEIVABLE & $298,133.53$ & $399,255.90$ & $455,991.15$ & $580,415.26$ \\
TOTAL ASSETS & $2,742,644.77$ & $3,471,657.33$ & $4,413,488.56$ & $5,766,016.44$ \\
CURRENT LIABILITIES & $1,182,306.22$ & $1,642,409.94$ & $1,838,695.85$ & $2,154,460.38$ \\
TOTAL LIABILITY & $1,298,336.31$ & $2,095,771.04$ & $2,357,822.14$ & $2,492,753.21$ \\
OWNERS' EQUITY & $1,444,308.45$ & $1,375,886.29$ & $2,055,666.42$ & $3,273,263.22$ \\
OPERATING INCOME & $3,891,114.14$ & $4,810,115.48$ & $5,748,269.81$ & $7,109,429.70$ \\
OPERATING COST & $3,219,892.15$ & $3,858,590.38$ & $4,616,516.66$ & $5,682,311.43$ \\
NET PROFIT & $47,562.79$ & $109,422.11$ & $416,078.49$ & $475,184.86$ \\
\hline
\end{tabular}

DATA SOURCE: 2014-2017 ANNUAL REPORT OF SF HOLDINGS

On October 11, 2016, SF obtained the consent of the China Securities Regulatory Commission, and successfully listed on the back of Maanshan Dingtai Rare Earth \& New Material Co., Ltd. Then on February 23, 2017, SF changed the name of the securities to "SF Holdings". As the current annual report for 2018 has not yet been published, in order to compare the financial performance of SF before and after listing, this article uses the financial indicators of the annual report from 2014 to 2017 for analysis. Among them, 2016 is the data during the backdoor listing, and 2017 is the data after the backdoor listing.

\subsection{Analysis of Solvency}

According to Table 1, the available solvency indicators: current ratio, quick ratio and asset-liability ratio are shown in Table 2.
TABLE 2 DEBT SERVICEABILITY INDICATORS

\begin{tabular}{ccccc}
\hline PROJECT & $2014-$ & $2015-$ & $2016-$ & $2017-$ \\
& $12-31$ & $12-31$ & $12-31$ & $12-31$ \\
\hline CURRENT & 1.33 & 1.13 & 1.16 & 1.46 \\
RATIO & & & & \\
QUICK & 1.29 & 1.12 & 1.14 & 1.44 \\
RATIO & & & & \\
ASSETS & $47.34 \%$ & $60.37 \%$ & $53.42 \%$ & $43.23 \%$ \\
AND & & & & \\
LIABILITIES & & & & \\
\hline
\end{tabular}

From the data in the table above, it can be seen that the change trend of the current ratio and the quick ratio is almost the same, and the difference between the two has been small. This is because in the express industry, inventory is relatively low, so it has less impact on both. Although from 2014 to 2015, the solvency indicators of SF showed that SF's solvency has weakened. However, after SF's decision to backdoor listing in 2016, SF's solvency has improved. By 2017, the current ratio has increased to 1.46, which is higher than 1.33 in 2014; and the asset-liability ratio has also decreased to $43.23 \%$, indicating that SF's solvency has improved, and the solvency after listing is better than before listing. 
In 2015, SF's solvency was weakened, and its assetliability ratio rose to $60.37 \%$. However, a high assetliability ratio does not necessarily mean that the corporate debt crisis is large. If the corporate borrowing capacity is strong, a high debt ratio is conducive to the expansion and development of the enterprise. SF has dominant position in the industry and has a strong ability to control funds. Moreover, the enhanced solvency in the next few years also shows that SF's financial risks are not significant.

In 2016, the company was undergoing a backdoor listing of asset restructuring, which had a large impact on the asset structure, resulting in changes in various indicators. In addition, sales income increased and net profit increased, making the current asset growth rate of $14.80 \%$, which is greater than the current debt growth rate of $12.00 \%$, so the current ratio increased.

In 2017, the short-term solvency index and long-term solvency index both increased significantly compared to 2016. Firstly, after SF Express is listed, it can issue bonds and equity financing on the secondary market, which can enhance its solvency. In addition, SF received 7.832 billion of non-public funds raised through backdoor listing, and the cash inflow has increased significantly compared with last year. In addition, the cash dividends paid in 2017 also decreased by 1.082 billion yuan compared with the previous year, so the current assets in 2017 increased significantly compared to 2016. Although the current liabilities also increased during the operating process, the overall growth rate was less than the growth rate of current assets, so the current ratio and quick ratio increased in the same direction from 2016 to 2017, indicating that SF Holdings' short-term debt-paying capacity was in 2017 . The year has improved.

In the first year (2017) after the listing of SF, in order to continuously expand its business scale, SF purchased more fixed assets and long-term assets. In addition, the 7.832 billion raised from the backdoor listing strengthened SF's solvency. The profits increased in 16 and 17 years, and the total asset growth rate was faster than the debt growth rate. Therefore, the asset-liability ratio decreased, and SF's long-term solvency was further enhanced.

After the listing of SF, the value of short-term solvency index is generally higher than before listing, and the value of long-term solvency index is lower than before listing, indicating that SF's solvency is stronger than before listing. In general, SF has raised more funds after listing, which provides a strong guarantee for the corporate solvency and reduces financial risks.

\subsection{Operational Capability Analysis}

According to Table 1, available operating capacity indicators: accounts receivable turnover rate and total asset turnover rate are shown in Table 3.
TABLE 3 OPERATING CAPACITY INDICATORS

\begin{tabular}{ccccc}
\hline PROJECT & $2014-$ & $2015-$ & $2016-$ & $2017-$ \\
\hline ACCOUNTS & $12-31$ & $12-31$ & $12-31$ & $12-31$ \\
$\begin{array}{c}\text { RECEIVABLE } \\
\text { TURNOVER } \\
\text { TOTAL }\end{array}$ & 13.05 & 12.05 & 12.61 & 12.25 \\
$\begin{array}{c}\text { ASSET } \\
\text { TURNOVER }\end{array}$ & 1.42 & 1.39 & 1.30 & 1.23 \\
\hline
\end{tabular}

As can be seen from the table above, the receivables turnover rate was 13.05 in 2014, but it fell to 12.25 in 2017. Although 2016 has increased compared to 2015, it has shown a general downward trend, indicating that SF's receivables use efficiency decreases. The turnover rate of total assets gradually decreased from 1.42 in 2014 to 1.23 in 2017, indicating that SF's use of total assets has also decreased slightly.

In 2016, in order to achieve the purpose of backdoor listing, the receivables and total assets scale caused by asset reorganization changed to a large extent. The growth rate of operating income in 2016 was greater than the growth rate of accounts receivable, so the turnover rate of accounts receivable increased.

However, the receivables turnover rate decreased slightly in 2017 because SF adopted regular settlement when providing services. In 2017, SF cooperated with UPS to expand international business cooperation and expand overseas markets. Although the operating income increased, with the continuous expansion of business scope, the scale of accounts receivable also increased. In 2017, the receivables grew at a rapid rate, which caused the receivables turnover rate to decrease slightly. However, it can be seen from the financial statements that most of its receivables will be recovered within one year, so the risks are relatively small.

Since 2014, SF has been continuously expanding its business scale and increasing the number of business services, so that its operating income and total assets have been increasing. In order to improve the service level, SF has increased the scale of fixed assets and investment real estate of enterprises through measures such as reorganizing assets listed on the backdoor, constructing airports, and purchasing aircraft. The growth rate of operating income lagged behind the growth rate of total assets, resulting in total asset turnover. The rate continues to decline slightly.

From the current financial indicators data, SF's operating capacity performance is worse than before listing. However, SF is currently in the strategic expansion stage, and the total asset turnover will only decrease temporarily. Operational capabilities should only be accumulated over a long period of time. Based on its relatively good operational capabilities before listing, coupled with capital and business increases, it can be predicted that SF's future operational capabilities will be better. 


\subsection{Profitability analysis}

According to Table 1, the profitability indicators are available: net operating margin, ROE and ROA, as shown in Table 4.

TABLE 4 PROFITABILITY INDICATORS

\begin{tabular}{ccccc}
\hline PROJECT & $2014-$ & $2015-$ & $2016-$ & $2017-$ \\
& $12-31$ & $12-31$ & $12-31$ & $12-31$ \\
\hline $\begin{array}{c}\text { NET } \\
\text { OPERATING } \\
\text { MARGIN }\end{array}$ & $1.22 \%$ & $2.27 \%$ & $7.24 \%$ & $6.68 \%$ \\
ROE & $3.36 \%$ & $7.95 \%$ & $20.24 \%$ & $14.52 \%$ \\
& & & & \\
ROA & $1.73 \%$ & $3.15 \%$ & $9.43 \%$ & $8.24 \%$ \\
\hline
\end{tabular}

As can be seen from the table above, from 2014 to 2016 , the net operating margin gradually increased from $1.22 \%$ to $7.24 \%$; the return on net assets increased from $3.36 \%$ to $20.24 \%$; and the return on total assets increased from $1.73 \%$ to $9.43 \%$. Although these three indicators have declined in 2017 , they are all higher than before listing, indicating that SF's profitability has increased.

In 2016, the net operating margin increased significantly to $7.24 \%$. This is because while expanding the market, SF also focused on improving the company's operating framework, accelerating operating efficiency, focusing on management of operating costs, and reducing management, resulting in a rise in net profit. And in 2016, SF acquired CHUI YUK HOIDINGS IIMITED and its subsidiaries, realizing a negative goodwill of 1.233 billion yuan, increasing net profit, so the operating net profit rate increased.

However, in 2017 , although SF transferred the equity of Hive BOX to achieve a net profit after tax of 874 million, it decreased by 359 million compared with the non-operating income of 1.233 billion in 2016; and due to the impact of environmental protection policies, cartons advocated by express packaging increase costs. In order to expand the market, a large amount of funds obtained after listing are used for operating costs, investment in basic equipment and personnel capacity development. In addition, SF has increased its investment in heavy cargo business and cold cargo transportation. In addition, SF has invested a lot of innovative capital in the research and development of the "aviation + ground + information" three-in-one integrated network resources.

The return on total assets and return on net assets in 2016 were significantly higher than their pre-IPO values. This was due to the increased ownership of non-targeted funds and the decrease in net profit, which resulted in a year-on-year decrease in return on net assets in 2017. $5.72 \%$, but still higher than the data before listing. Therefore, after the listing of SF, the efficiency of fund use has increased, profitability has improved, and business operations have been expanded.

After the listing of SF, the profitability increased, which indicates that the advertising effect of backdoor listing and capital power can improve the short-term profitability of enterprises. It implies that SF's own strong strength. Coupled with the financing capabilities of the capital market, SF's development prospects are bright.

\subsection{Growth ability analysis}

According to Table 1, the available growth capacity indicators: net profit growth rate, operating income growth rate, and total asset growth rate are shown in Table 5 .

TABLE 5 GROWTH ABILITY INDICATORS

\begin{tabular}{ccccc}
\hline PROJECT & $2014-$ & $2015-$ & $2016-$ & $2017-$ \\
& $12-31$ & $12-31$ & $12-31$ & $12-31$ \\
\hline NET & - & & & \\
PROFIT & 74.03 & 130.06 & 280.25 & 14.21 \\
GROWTH & $\%$ & $\%$ & $\%$ & $\%$ \\
RATE & & & & \\
OPERATIN & & & & \\
G INCOME & 42.11 & $23.62 \%$ & $19.50 \%$ & $\begin{array}{c}23.68 \\
\text { GROWTH }\end{array}$ \\
RATE & & & & $\%$ \\
GROWTH & & & & \\
RATE OF & 30.76 & $26.59 \%$ & $27.13 \%$ & 30.65 \\
TOTAL & $\%$ & & & $\%$ \\
ASSETS & & & & \\
\hline
\end{tabular}

As can be seen from the above table, all indicators of 2017 in the first year of listing have been increasing, indicating that SF's growth is better.

SF restructured assets and acquired other high-quality assets in 2016 and Taisen Holding invested 3.922 billion yuan in SF Holdings, which caused a huge change in the net assets and total assets of SF Holdings. In 2016, the increase in non-operating income and cost reduction in the backdoor listing made the net profit as high as 4,167.4849 million yuan, a huge increase compared to 2015, and the publicity and advertising effects of backdoor listing increased business and increased operating income. All indicators are growing positively.

SF formulated a series of strategic activities in 2017 to further increase its operating income and total assets. First, in order to promote the growth of cross-border service business, SF established a joint venture with UPS Group to set up Global Express Holdings Limited to expand SF's international business. Secondly, SF's subsidiaries signed strategic cooperation with China International Marine Containers (Group) Co., Ltd. On the basis of the operating characteristics, the companies broaden win-win economic cooperation. Finally, to improve the layout of SF Holding's national air transport network, Shunfeng Taisen, a wholly-owned subsidiary of the Company, signed the "Hubei International logistics Hub project Cooperation Agreement" with Hubei provincial people's Government. And in 2017, SF also repeatedly issued bonds to its subsidiaries.

SF is currently in a strategic expansion period. The capital advantage after listing has laid the foundation for SF's development. It can also be seen from the positive growth rate that SF has strong development power, good growth potential and huge development space. 


\subsection{Horizontal comparison of financial performance}

In the express delivery industry, most of the leading companies that have faced huge funding pressures have chosen to backdoor listing; however, in 2018, DEPPON Express took a different approach and became the first IPO company in the express delivery industry. This section compares the data from the first three quarters of the first year (2017) of SF backdoor listing with the first three quarters of the first year (2018) of DEPPON, and discusses the impact of the listing method on corporate financial performance. Due to the short time span, only comparative analysis of solvency, operating capacity and profitability is performed here.

\subsection{Comparison of Solvency}

The data on the solvency index comes from Guotai'an database, as shown in Table 6.

TABLE 6 COMPARISON OF SF AND DEPPON 'S SOLVENCY

\begin{tabular}{|c|c|c|c|c|c|c|}
\hline $\begin{array}{l}\text { PROJ } \\
\text { ECT }\end{array}$ & \multicolumn{3}{|c|}{ SF } & \multicolumn{3}{|c|}{ DEPPON } \\
\hline TIME & $\begin{array}{c}2017 \\
/ 03 / 3 \\
1\end{array}$ & $\begin{array}{c}2017 \\
/ 06 / 3 \\
0\end{array}$ & $\begin{array}{c}2017 \\
/ 09 / 3 \\
0\end{array}$ & $\begin{array}{c}2018 \\
/ 03 / 3 \\
1\end{array}$ & $\begin{array}{c}2018 \\
/ 06 / 3 \\
0\end{array}$ & $\begin{array}{c}2018 \\
/ 09 / 3 \\
0\end{array}$ \\
\hline $\begin{array}{c}\text { CUR } \\
\text { RENT } \\
\text { RATI } \\
\text { O }\end{array}$ & 1.16 & 1.13 & 1.63 & 1.32 & 1.29 & 1.28 \\
\hline $\begin{array}{c}\text { QUIC } \\
\text { K } \\
\text { RATI } \\
\text { O }\end{array}$ & 1.14 & 1.11 & 1.61 & 1.32 & 1.29 & 1.27 \\
\hline $\begin{array}{c}\text { ASSE } \\
\text { TS }\end{array}$ & & & & & & \\
\hline $\begin{array}{l}\text { AND } \\
\text { LIABI } \\
\text { LITIE }\end{array}$ & $\begin{array}{c}50.6 \\
3 \%\end{array}$ & $\begin{array}{c}50.8 \\
3 \%\end{array}$ & $\begin{array}{c}41.9 \\
2 \%\end{array}$ & $\begin{array}{c}50.5 \\
4 \%\end{array}$ & $\begin{array}{c}55.1 \\
3 \%\end{array}$ & $\begin{array}{c}55.9 \\
6 \%\end{array}$ \\
\hline $\mathrm{s}$ & & & & & & \\
\hline
\end{tabular}

As can be seen from the data in the table above, SF's solvency decreased slightly in the second quarter after listing, but increased significantly in the three quarters: the current ratio rose to 1.63 , the quick ratio rose to 1.61 , and the asset-liability ratio decreased To $41.92 \%$. Overall, SF's solvency has strengthened. DEPPON 's short-term solvency decreased slightly over time, with the assetliability ratio rising from $50.54 \%$ to $55.96 \%$. It shows that DEPPON 's solvency has weakened in the three quarters before the first listing.

Comparing the two companies' first two quarters after listing, DEPPON Express's current ratio and quick ratio are higher than SF, which indicates that DEPPON Express's short-term solvency is better at this time. But by the third quarter, SF's short-term solvency indicators rose sharply, surpassing DEPPON Express. In the first quarter, DEPPON Express's asset-liability ratio was slightly lower than that of SF.41.92\%This shows that SF Holdings has a stronger long-term solvency than DEPPON.
Mainly because SF received targeted fundraising, with total assets of 54.157 billion yuan and net assets of 31.452 billion yuan at the end of the third quarter, the SF assetliability ratio fell in the third quarter of the first year of listing. In addition, SF's debt is mainly short-term, coupled with the issuance of bonds by Taisen Holdings, a wholly-owned subsidiary of SF Holdings, which further optimizes SF's asset structure and enhances its short-term solvency. However, one of the main characteristics of DEPPON Express Finance is its high debt ratio, the use of financial leverage, and greater financial risk. So overall, in the first year of listing, SF's solvency was stronger than DEPPON's.

\subsection{Comparison of operating capabilities}

The operating capacity index data comes from Guotai'an database, as shown in Table 7.

TABLE 7 COMPARISON OF OPERATING CAPACITY BETWEEN SF AND DEPPON

\begin{tabular}{c|ccc|ccc}
\hline PROJE & & & & \multicolumn{3}{c}{ DEPPON } \\
CT & \multicolumn{3}{|c|}{ SF } & & \multicolumn{3}{c}{ DE } \\
& 2017 & 2017 & 2017 & 2018 & 2018 & 2018 \\
TIME & $/ 03 / 3$ & $106 / 3$ & $/ 09 / 3$ & $/ 03 / 3$ & $106 / 3$ & $109 / 3$ \\
& 1 & 0 & 0 & 1 & 0 & 0 \\
\hline ACCO & & & & & & \\
UNTS & & & & & & \\
RECEI & & & 10.7 & 5.17 & 10.8 & 16.2 \\
VABL & 3.78 & 7.38 & 8 & & 0 & 5 \\
E & & & & & & \\
TURN & & & & & & \\
OVER & & & & & & \\
TOTA & & & & & & \\
L & & & & & & \\
ASSE & 0.36 & 0.72 & 0.92 & 0.65 & 1.26 & 1.87 \\
T & & & & & & \\
TURN & & & & & & \\
OVER & & & & &
\end{tabular}

It can be seen from the data in the above table that the turnover rate of SF's receivables rose from 3.78 to 10.78 ; the turnover rate of total assets rose from 0.36 to 0.92 . DEPPON 's account receivable turnover rate rose from 5.17 to 16.25 , and the total asset turnover rate rose from 0.65 to 1.87 . In the first three quarters of the listing of SF and DEPPON, both the accounts receivable turnover rate and the total asset turnover rate showed a gradual upward trend, and their operating capabilities improved.

However, comparing the two sets of data, we can see that the data of the accounts receivable turnover rate and total asset turnover rate of SF Holdings are much lower than DEPPON Express in each quarter. Comparing the growth ratio, we can see that DEPPON 's account receivable turnover rate has increased even faster. In the same way, DEPPON 's total asset turnover rate is growing faster than SF.

Although the operating income of the two companies increased in each period, SF received the targeted funds raised in the third quarter of the first year of listing, resulting in a larger increase in total assets, resulting in a 
smaller total asset turnover growth rate than DEPPON. And DEPPON often uses financial leverage. Although financial risks are high, it can improve operating efficiency.

\subsection{Profitability Comparison}

The profitability indicator data comes from Guotai'an database, as shown in Table 8.

TABLE 8 PROFITABILITY COMPARISON BETWEEN SF AND DEPPON

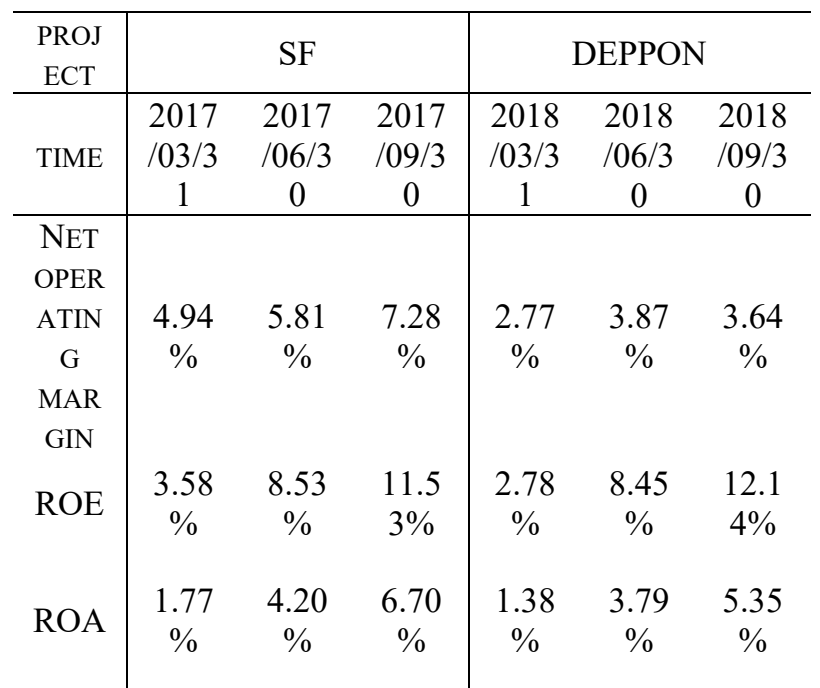

As can be seen from the above table, SF's operating net margin has increased more than DEPPON; SF's ROE has risen to $11.53 \%$, ROA has risen to $6.70 \%$; DEPPON 's ROE has increased to $12.14 \%$, and ROA has risen to $5.35 \%$. It can be seen that after listing, the profitability of both companies has significantly increased.

In terms of operating net profit margin, SF Holdings' quarterly operating net profit margin and its growth rate are higher than DEPPON Express. The total net asset rate of SF Holdings is also higher than that of DEPPON Holdings; only in the third quarter of 2018, the return on net assets of DEPPON Express was higher than that of SF Holdings. Most of SF's profitability indicators are higher, indicating that SF's profitability is stronger than DEPPON.

The operating income and net profit of SF and DEPPON in the first three quarters have increased significantly compared with the same period last year. SF's International Express, Intra-city instant delivery, Heavy Cargo and Cold Chain for food products are growing at an alarming rate, and business volume is also increasing. At the same time, DEPPON focused on the development of the Heavy Cargo market, focusing on logistics products in the $3 \mathrm{~kg}-60 \mathrm{~kg}$ market, and received a good response. However, due to SF's focus on cost control, SF's sales expenses and management expenses in the first three quarters were about 6.2 billion, a growth rate lower than operating income; and financial expenses were only 187 million, a year-on-year decrease of $38.55 \%$. And with a large amount of capital investment, DEPPON is currently in the construction period of the large-scale express warehousing supply chain; and the investment of DEPPON 's direct operation model is greater than SF's, making DEPPON 's comprehensive gross profit rate of $14.58 \%$ The interest rate is $18.91 \%$ ). Therefore, the investment cost of DEPPON is relatively large, resulting in relatively weaker profitability.

\section{Research results and recommendations}

\subsection{Research results}

After SF backdoor listing, it continued to develop new businesses, improve differentiation, and consolidate the company's overall competitiveness and ability to resist risks. Debt solvency and profitability are on the rise, and the growth of the listed is good; although operating capacity is weaker than before listing, it is gradually improving. So overall, SF's financial performance is better than before listing.

DEPPON Express took a different approach and Select IPO. In the first three quarters after the listing, the solvency decreased, but the operating capacity and profitability increased. Comparing the financial performance of the first three quarters of the listing, it was found that SF's solvency and profitability are stronger than DEPPON Express, and DEPPON Express's operating capability is significantly better. Each advantage. Overall, the positive impact of backdoor listing on financial performance is greater than IPO.

This paper finds that backdoor listing is conducive to better short-term financial performance of the company, and that the financial performance of backdoor listing in the first year of listing is better than IPO listing. However, some scholars use longer-term data research to find that in the long run, the listing method has little effect on financial performance. The shortcoming of this article is that the time span of the financial indicators used is short, and only a short-term comparison of financial indicators is analyzed, which has little significance for long-term reference.

However, in the short term, after SF's listing, its financial performance has improved significantly, and its effectiveness is also better than that of DEPPON, which is an IPO.

\subsection{Policy recommendations}

The ultimate purpose of the company's choice of listing financing is for production and operation. Therefore, a company that wants to go public should first clarify the actual situation of its own company, combine its financial characteristics and the degree of capital requirements, and choose a suitable listing method.

DEPPON Express chose IPO mainly because DEPPON is a "little load" logistics company with good profitability, sufficient bank credit lines for corporate development, and DEPPON 's development funds are sufficient; and DEPPON 's comprehensive valuation is high, so looking for shell Resources is more difficult. Therefore, DEPPON chose IPO. SF's backdoor listing is mainly due to the urgent need for funds and strict IPO review 
If a company chooses an IPO, it should consider whether internal financing and debt can meet the development of the company in a timely manner, and whether the company itself can meet the financial assessment and access mechanism, and can withstand the waiting time of the IPO.

Companies that choose to backdoor listing should understand that although backdoor listing is short, they also face risks and costs. The first is the risk of information asymmetry; the second is the audit risk. Since the introduction of new rules for asset reorganization in 2016, the review of asset reorganization during the backdoor listing process has also been stricter. Finally, there are financing risks, shell purchase, and asset placement require huge capital strength. The risk of financing costs is high.

Finally, the organization of the strategic goals of the company after listing is the most critical. Because no matter which listing method is selected, companies should carefully understand their own strength and status, improve their operating capabilities, profitability and growth capabilities, and standardize corporate behavior, improve corporate structure, and timely correct existing problems in order to grow in fierce competition.

\section{Analysis conclusion}

Since the introduction of new rules for asset reorganization in 2016, it is more difficult for companies planning to list to use backdoor approval procedures to engage in "institutional arbitrage". At the same time, companies planning to list through IPOs also have the high opportunity cost of strict IPO review. As a leading company in China's express delivery industry, SF's successful backdoor listing not only has an important impact on the growth-shifting express delivery industry, but also has an important reference to other companies to be listed. This paper discusses the motivation and purpose of SF Express's backdoor listing, and then analyzes the financial indicators before and after SF listing from a horizontal and vertical comparison to demonstrate the impact of backdoor listing on corporate financial performance. The conclusions of this paper are as follows:

First, different enterprises should choose suitable listing schemes according to their own financial characteristics and understand the risk and the strategic goal of the enterprise's own development. Regardless of whether the company is listed by backdoor listing or IPO, listing can help companies enter the capital market and raise funds, thereby developing new businesses and seizing new market, which helps the company keep up with the Industry development trends. SF Express is still in a period of strategic expansion, and its service positioning is to provide high-quality logistics services at the distribution end. Therefore, SF's current development requires a lot of capital. By comparing the financial indicators of SF Express before and after listing vertically, we found that after SF's backdoor listing, its operating income continued to increase and its solvency and profitability are on the rise. The types of SF's business services are constantly increasing, and the corporate structure is becoming more and more perfect. SF Express's operating capabilities and growth prospects are optimistic, and SF's overall financial performance has developed significantly better. DEPPON Express is the first express company in China's IPO and the first share of China LTL Logistics. Comparing the financial performance of the first three quarters of the listing horizontally, it was found that DEPPON Express's operating capacity and profitability have improved. In the first half of 2018, DEPPON Express's express delivery volume and express delivery revenue both increased year-on-year, and the express delivery ticket revenue was also higher than the industry average.

Second, the financial performance of backdoor listing in the short term is better than that of IPO. Through a comparative analysis of the financial performance of the first three quarters of DEPPON and SF Express, it was found that the overall solvency and profitability of SF Express is stronger than that of DEPPON Express. In terms of overall short-term data, SF Express 's financial performance is better than DEPPON Express. In other words, the financial performance of backdoor listing is better than that of IPO. However, because the time span of SF's backdoor listing and DEPPON 's IPO is relatively short, we can only obtain short-term limited financial indicators onto present. Similarly, it is impossible to track and judge the long-term impact on IPO listing on DEPPON 's financial performance. Therefore, the research results have a certain timeliness and have little significance for long-term research.

\section{References}

[1] Chen Zheng. Proposals for Chinese SMEs to Be Listed in the US [J]. Finance and Accounting, 2014 (01) 57.

[2] Chen Qianyun. Talking about the trading structure and performance of Ciwen Media's listing on the "net" shell [J]. Finance and Economics (Academic Edition), 2016 (16) 43.

[3] Cao Shufang, Su Jun. Analysis of the accounting treatment of backdoor listing under different transaction structures-based on the case of the reorganization of United Chemical and Jiangsu Hongbao [J]. Chinese Certified Public Accountant, 2014 (12): 96-100.

[4] Dai Juanping. Analysis of the Motivation of Greenland Group's Backdoor Listing [J]. Finance and Accounting, 2015 (22): 29-31.

[5] Dou Zhi. Motives and Suggestions for Backdoor Listing [J]. Shang, 2016, (30): 185.

[6] Feng Baiyang. Problems and Reflections on the Private Listed Express in China's Competitive Listing [J]. Commercial Economy, 2016 (7): 29-30.

[7] Gao Yiyi. Research on Backdoor Listing of Enterprises [J]. Shopping Mall Modernization, 2018 (12): 150-152.

[8] Gong Siyi. Backdoor listing of private express delivery enterprises in China [J]. China Business Review, 2017 (11): 115-116.

[9] Liu Qing, Yang Zifeng. Research on the Follow-up Financial Performance of Chinese Enterprises' Backdoor Listing Based on Principal Component 
Analysis [J]. Journal of Liaoning Normal University (Natural Science Edition). 2018 (1): 23-25.

[10]Luo Shiyi, Wang Jie, Shuai Xu Fei. Talking about Backdoor Listing [J]. Modern Business, 2013 (8): 195.

[11]Li Sha. Reflections on the Issue of Backdoor Listing_A Case Study of Kaidi Investment Backdoor Listing [J] .Time Finance, 2014 (8): 173174.

[12]Lin Xiang.Yuantong Express Backdoor Listing Performance and Its Motivation Analysis [D] Guangdong University of Technology, 2017.

[13] Li Xiaojing. An Analysis of the Motivation of Backdoor Listing in China [J]. Shang, 2016,25: 161.

[14]Jiang Shuangna.Performance Research Based on Reverse Mergers and Acquisitions Model of Securities Companies [D] .Zhenjiang: Jiangsu University, 2011.

[15] Ju Fanglin.Follow-up Performance of Backdoor Listed Companies [D] .Dongbei University of Finance and Economics, 2015.

[16] Ma Xinyue. Performance comparison of backdoor listing and IPO companies based on multiple linear regression $[\mathrm{J}]$. Science \& Technology Economics Guide, 2018,26 (34): 177-179.

[17] Ma Leihui. Evolution and Motivation of Backdoor Listing in China [J]. Modern Business, 2015 (06): 168-169.

[18]Peng Xiaojie. The status quo, motivations and suggestions of backdoor listing of private enterprises in China [J]. Journal of Finance and Accounting Monthly, 2011,12.28-29.

[19] Pan Ying, Nie Jianping. Evaluation of M \& A Performance Differences of Listed Companies Based on Cause Analysis [J]. Economic Issues, 2014 (01).

[20]QIU Qun. Research on the financial performance of real estate companies backdoor listing $[\mathrm{J}]$. Finance and Economics (Academic Edition), 2013 (18): 188 +230 .
[21] Wang Dong, Chen Jianli. Analysis of issues related to backdoor listing of enterprises $[\mathrm{J}]$. Cooperative Economy and Science and Technology, 2018 (23): 142-143.

[22] Wu Zhisong. Application of "backdoor listing" in financing of small and medium-sized real estate companies [J]. Friends of Accounting, 2014 (09).

[23] Wu Congcong.A case study of Yuantong Express's backdoor listing [D]. Shenzhen University, 2017.

[24]Xiao Min. Capital Market Choice for Backdoor Listing of Enterprises $[\mathrm{J}]$. Finance and Accounting Newsletter (Finance), 2007 (5): 23-26.

[25] Shi Xinke. A Probe into the Backdoor Listing of the Logistics Industry After the Release of the Newest Regulations of the Most Serious Group [J]. Science \& Technology Economics Guide, 2018,26 (30): 144$145+147$.

[26] Xu Wei, Pei Zhehui. Motives, problems and countermeasures of back-listing of private enterprises [J]. Modern Management Division, 2011 (8): 99-100.

[27] Sun Peidong.Empirical Research on Corporate Performance under Different Listing Methods [D] .Shandong: Shandong University of Finance and Economics, 2014.

[28] Xia Jin. Theoretical Summary and Typical Cases of China's Overall Listing Mode [J]. Modern Business, 2010,2: 184-185.

[29]Zhao Chengye. How Real Estate Companies Choose Backdoor Listing [[J]. International Finance, 2009 (3) 35-38.

[30]Zhang Xiaoqian. An Empirical Study on the Performance of Corporate $M$ \& A [J]. Consumer Guidance, 2009 (2): 7.

[31]Zhang Huan. A Comparative Study of Backdoor Listing and Subsequent Performance of IPO Companies [J]. Research on Development Finance, 2015 (3): 33-45.

[32] Zhao Hong. Research on the Motivation and Financial Performance of Shentong Express's Backdoor Listing [J]. Hebei Enterprises, 2018 (08): 121-122. 